\title{
Ethics, economics, and public financing of health care
}

Jeremiah Hurley McMaster University, Hamilton, Ontario, Canada

\begin{abstract}
There is a wide variety of ethical arguments for public financing of health care that share a common structure built on a series of four logically related propositions regarding: (1) the ultimate purpose of a human life or human society; (2) the role of health and its distribution in society in advancing this ultimate purpose; (3) the role of access to or utilisation of health care in maintaining or improving the desired level and distribution of health among members of society, and (4) the role of public financing in ensuring the ethically justified access to and utilisation of health care by members of society. This paper argues that economics has much to contribute to the development of the ethical foundations for publicly financed health care. It focuses in particular on recent economic work to clarify the concepts of access and need and their role in analyses of the just distribution of health care resources, and on the importance of economic analysis of health care and health care insurance markets in demonstrating why public financing is necessary to achieve broad access to and utilisation of health care services.

(Fournal of Medical Ethics 2001;27:234-239)
\end{abstract}

Keywords: Ethics; economics; health care financing

\section{Introduction}

Is there an ethical rationale for publicly financed health insurance? It would seem there is a variety of (sophisticated, complex, and sometimes mutually incompatible) arguments rooted in different ethical frameworks. However, because public financing is a particular institutional arrangement that is valued not intrinsically but only to the extent that it contributes to achieving a higher end, a wide variety of such arguments share a common structure. Although these arguments differ considerably in detail, they share a structure built on four logically related propositions regarding: (1) the ultimate purpose of a human life or human society; (2) the role of health and its distribution in society in advancing this ultimate purpose; (3) the role of access to or utilisation of health care in maintaining or improving the desired level and distribution of health among members of society, and (4) the role of public financing in ensuring the ethically justified access to and utilisation of health care by members of society. Because the dominant concern of modern economic analysis is the consequences of alternative institutional arrangements of economic activity, economic reasoning has much to contribute to the development of such ethical arguments. Indeed, economic analysis is a necessary ingredient since the rationale for public financing rests at least in part on demonstrating that the ethically required access to and utilisation of health care cannot be achieved through a system of solely private financing. Equity arguments alone are not sufficient: if markets function well a system of public subsidies for the purchase of private insurance could deal with equity concerns. Rather, full public financing for health care requires demonstrating that, even in the presence of appropriate subsidies, private financing through insurance markets fails to promote the requisite access to or utilisation of health care. Economic reasoning is crucial to any ethical argument that proceeds in this fashion.

The paper is organised around the four propositions listed above, focusing on propositions (3) and (4) where economics offers the greatest potential contributions. To help make matters more concrete, I illustrate key points with reference to ethical analysis of public financing within three specific ethical frameworks: (1) classical utilitarianism; (2) extra-welfarism, particularly as developed in the health sector ${ }^{23}$; and (3) Rawlsian-style contractarianism. ${ }^{45}$ I choose these because they are commonly used in health sector analysis, they represent broad approaches to social ethics for which there are numerous particular refinements, they differ in their focus for valuation and in the decision rules used to rank institutional arrangements, and they derive from very different philosophical and ethical traditions. Space constraints mean that I can give each only the most cursory treatment; their use is meant purely to illustrate points, not to develop the fundamental argument.

\section{The structure of ethical arguments} regarding public financing of health care THE PURPOSE OF LIFE, ULTIMATE ENDS AND A JUST SOCIETY

The purpose of life has of course been a central question in moral and political philosophy for thousands of years and a question to which philosophers have provided a wide range of answers. All theories of justice and the "good" society are based (implicitly or explicitly) on such an ultimate end, and within any such theory the characteristics of a just society are those that foster the posited ultimate end. For Bentham, Mill and classical utilitarians the ultimate human end was 
happiness and the good society maximised happiness among its members. Extra-welfarists, in contrast, eschew utility in favour of more objective outcomes such as functionings and capabilities and the good society allocates resources to foster these among its members. ${ }^{6-8}$ For Rawls the ultimate end was "the satisfaction of [a person's] rational desire" in the form of a rational plan of life, ${ }^{9}$ and in a good society deviations from equality of basic primary goods can be justified only to the extent that they improve the lot of the least advantaged member of society. ${ }^{4}$

HEALTH

Health is ethically good to the extent that it contributes to the realisation of the ultimate end sought-happiness, capabilities and functionings, fulfilment of a rational life plan, etc. Among the various "goods" that contribute to the ultimate end, health is often accorded special ethical significance because it is necessary to achieving most intermediate and ultimate ends; ill health and injury are unpredictable and largely beyond the control of an individual (most of those who fall ill have done nothing knowingly to deserve or cause the ill health); and ill health represents a time of considerable vulnerability and dependency on others, giving society's response to those who suffer illness and injury particular ethical salience.

But simply arguing that health is ethically important is not enough. A crucial question is: what does an ethical analysis demand about the just level and distribution of health in society. Maximising the level of health in society is unlikely to be ethically justified given that health is only one contributor to an ultimate end and that health cannot be directly redistributed among members of society (though of course it can be indirectly redistributed via the allocation of health-influencing resources). Welfarist reasoning cannot identify the just distribution of health a priori because the just distribution depends on the structure and distribution of preferences in society with respect to health and other things. The just level and distribution of health is the one that maximises average utility among members of society. If one assumes diminishing marginal utility, then utilitarianism would have a bias toward more equal distributions of health (up to the point where the additions to utility from this are offset by reductions in utility from transferring additional resources from other activities to health). From an extra-welfarist health perspective, Culyer and Wagstaff argue that the only ethically defensible distribution of health is an equal distribution, subject to some side constraints such as the imperative not to deliberately reduce one person's health status to equalise health levels. ${ }^{10}{ }^{11}$ Rawls did not include health or health care in his set of primary goods, but more recently he has explored how health might be integrated into his framework. ${ }^{12}$ Rawls's difference principle would permit a deviation from an equal distribution of health if it improved the health and wellbeing of the least advantaged member of society; it is silent on the characteristics of the distribution above this minimum level. (See Williams and Cookson ${ }^{13}$ for an analysis within an economic framework of the demands of a wide variety of equity criteria with respect to the distribution of health among members of society.)

ACCESS TO AND UTILISATION OF HEALTH CARE

Health care, which is generally defined to include those goods, services and activities the primary purpose of which is the maintenance or improvement of health ${ }^{14}$ is one of a complex array of factors that determine health. ${ }^{15}$ Health care as such is not intrinsically ethically valuable; it is ethically valuable because it contributes to health. From this it follows directly that the ethically justified distribution of access to and utilisation of needed health care is the one which generates the desired level and distribution of health.

This conclusion rests on two controversial, often confusing concepts-access and need-central to many discussions of ethics and health care. Economic reasoning has contributed in recent years to clarifying access, need and competing definitions of these concepts (see, for example Culyer and Wagstaff, Mooney, Le Grand, Pereira, and Wagstaff and Van Doorslaer ${ }^{10}{ }_{16-20}$ even if it may not have generated greater consensus. Economics identifies access with the concept of feasible choice sets. $^{101822}$ A person's feasible choice set includes all those things it is possible for them to obtain or accomplish given their resources and constraints beyond their control. Therefore, access is greater in situation $\mathrm{B}$ compared to situation $\mathrm{A}$ if the feasible choice set under B is larger than (and fully encompasses) the feasible choice set in A. Two individuals have equal access if they have identical feasible choice sets. Empirically measuring access remains a tremendous challenge, but this analytic approach provides considerable insight into the implications for resource allocation of calls for differing types of access.

It is not access to or utilisation of health care services as such that is ethically justified, but access to or utilisation of needed health care services. The notion of need is highly contested, ${ }^{21}{ }^{23-28}$ but economists generally favour instrumentalist conceptions of need: a need exists when there is a good, activity or service that is effective (and some would add cost-effective ${ }^{23}$ ) in attaining an ethically legitimate end for a person. The question of effectiveness is in large part technical; the question of what constitutes an ethically legitimate end is in large part social, political and moral. Unlike most areas of economics, for which goods are assumed to contribute directly to welfare, the technical production relationship between health care and health allows for a more precise use of the concept of need than is possible even in other areas where needs talk is prevalent (for example, housing, food, education). This production relationship means that a health care need is very specific-one needs a specific health care service that has been shown to be effective for the particular health problem, for 
which there are often few substitutes. Unlike most goods, health care itself is often a "bad" that causes considerable short term pain and suffering, but which is consumed only because of its expected health benefits. This provides a sounder basis for third party judgments of need, especially need in relation to socially defined objectives.

The fact that the primary purpose for consuming health care is to improve health and that there is a basis for third-party judgments of need (as opposed to mere wants) generates good-specific distributional concerns about health care. Welfarist frameworks model this through utility interdependences that generate good-specific caring externalities associated with health status and the consumption of needed health care. ${ }^{29} 30$ That is, person A's utility depends in part on person B's health status and, by implication, her consumption of needed health care; where access itself is the focus of concern, person A's utility depends in part on person B's access to health care (though person B may choose not to consume even needed care).

Welfarists seldom investigate the underlying source of such utility interdependence (for example, the view that health care is a right, notions of solidarity with other members of society, etc), but regardless of that, such externalities imply that within welfarist frameworks broad access to and utilisation of needed health care may be ethically justified. As ever, the preferred distribution depends on the precise nature of preferences and utility interdependences, but a priori such externalities give rise to distributional concerns not associated with most goods and services. Culyer and Wagstaff's health-oriented extra-welfarism calls for access to and utilisation of health care services that generate an equal distribution of health. This will call for broad access to health care services for all members of society, though they specifically note that the ethically justified distribution is unlikely to coincide with allocation according to need and equal access to health care. ${ }^{10} \mathrm{~A}$ Rawlsian demand for a minimal level of health for all in society would also demand a minimal level of access to or utilisation of needed health care services by all in society.

What is noteworthy is that each of these frameworks calls, to some extent, for utilisation of health care to be associated with need and health status, not simply ability to pay, and that this fact demands broad (but not necessarily equal) access to needed health care services by all members of society.

THE ROLE OF PUBLIC FINANCING

The last link in the chain of reasoning is the demonstration that public financing of health care is either necessary to generate the ethically justified distribution of access and utilisation or that it does this better than other financing arrangements. This requires examining the properties of alternative private market and public financing arrangements. In the discussion I distinguish four configurations of financing with increasing reliance on public financing: (1) fully private financing through private insurance purchases and direct payments by patients to providers; (2) public subsidies to support the purchase of insurance in private markets, and/or public insurance for certain population sub-groups (for example, as in the US); (3) single-source, universal, first-dollar (free of charge) publicly financed insurance, with a parallel private insurance sector offering coverage for the same services insured by the public sector (for example, as is the case in the UK); and (4) single-source, universal, first-dollar publicly financed insurance with no parallel private insurance sector (for example, as is the case for physician and hospital services in Canada).

\section{Insurance, insurance markets, and financing health care}

Unpredictability in the need for health care and the high costs of health care (which can exceed an amount that even many forward-looking, prudent members of society could afford) generate an important role for insurance in health care financing. Insurance pools individuals' financial risks associated with health care, reducing the total amount of risk in society and allowing those who fall ill to obtain the care they need. From an ethical perspective, it is interesting to note that, unlike most goods and services, the production of insurance is by definition a collective activity: it is literally impossible for a single individual to "produce" insurance (except in the very limited sense of pooling risk over time through saving). One can produce insurance only by joining together with others (even if through market-based, voluntary transactions) to form a risk pool.

A system of private insurance markets alone (even one that is well-functioning by economic criteria discussed below) could not provide the broad access called for by the analysis in the previous section. Markets allocate goods and services on the basis of a person's ability and willingness to pay. Low-income members of society would be unable to afford health care insurance policies. This is particularly so given the well-established inverse relationship between socioeconomic status and health status, which would make premiums in a private market highest on average for those with the fewest economic resources (and the most need). From an economic perspective, however, this is simply a problem of the distribution of income. If health care insurance markets are otherwise wellfunctioning, all that may be required to address this problem is a system of public subsidies to allow the purchase of health care insurance by all members of society.

A role for public financing beyond a system of subsidies for private insurance depends on how well a system of private health care insurance markets functions, or, in economic language, the extent to which markets fail to allocate resources efficiently. Economics defines a situation to be efficient if one beneficial activity cannot be increased without decreasing some other beneficial activity. ${ }^{31}$ The ethical force of this concept of efficiency within a 
consequentialist line of reasoning is clear: to tolerate an inefficient allocation of resources is to forgo an opportunity to provide benefit (however one wants to measure this) to one person or group without decreasing benefit to anyone else.

Within this broad concept, economists distinguish three types of efficiency. Technical efficiency requires that we not waste physical or human resources when producing goods and services. Cost-effectiveness efficiency integrates the relative costs of resources, and requires that we use the least-cost combination of inputs to produce goods and services. And allocative efficiency integrates a consideration of the value of goods and services to members of society. It asks whether society is producing the "right" amount of each good and service and distributing those goods and services in accord with the "value" individuals place on them. The "right" mix and distribution of goods depends, of course, on how value to an individual is assessed (utility, health, other notions of wellbeing) and on the decision-criterion by which different allocations are ranked, (for example, a maximisation criterion, a Pareto criterion, a Rawlsian maxmin criterion).

\section{Economies of scale}

Private health care insurance markets suffer from two sources of technical inefficiency that can be mitigated or avoided through public financing. The fixed costs to a private insurer of providing insurance (for example, the cost of determining risk-rated premiums), which are the same whether the insurer sells 100 policies or 100 million policies, generate economies of scale in insurance provision that make it impossible in many settings to sustain competitive markets for insurance if firms are to operate at technically efficient sizes. ${ }^{32}$ In addition, systems of private insurance with multiple insurance organisations are technically inefficient because they require a host of administrative costs absent from public insurance programmes (for example, rate-setting, marketing, claims administration). Estimates suggest, for example, that administrative costs within the private, multi-payer US system account for $19-24 \%$ of health care spending while they account for only $8-11 \%$ in Canada's publicly financed system. ${ }^{33}$

Allocative inefficiency in private insurance markets that arises from informational asymmetries between sellers and purchasers of insurance further supports the argument that public financing is necessary to achieve broad access to health care. In private insurance markets that form risk pools by voluntary enrolment, informational asymmetries between insurance providers and insurance purchasers can cause risk selection. Risk selection arises when insurers selectively enroll low-risk individuals (cream-skimming) or when high-risk individuals selectively seek out more generous insurance (adverse selection). Risk selection, and adverse selection in particular, can make it impossible to sustain private insurance markets. As a consequence, even people who are willing and able to purchase insurance at a price that reflects their risk status are unable to do so because the dynamic of adverse selection makes it impossible to sustain an insurance market. Although risk-adjusted premiums can reduce such risk selection, it is not possible to risk-adjust premiums accurately enough to eliminate risk selection. Universal, publicly financed insurance that covers all residents of a jurisdiction completely avoids risk selection.

Asymmetry of information between patients and health care providers furnishes an additional rationale for public financing and for first-dollar coverage with no patient cost-sharing. Individuals are frequently unable to identify what is wrong with them and, once diagnosed, what health care services they need to resolve their health problem. A primary reason for seeing a health professional is precisely to obtain such information. This informational asymmetry gives health care providers tremendous market power and can generate inefficiency-inducing supply-side moral hazard (higher prices, increased use of marginally beneficial services). Moral hazard plagues both privately and publicly financed insurance systems, but public insurers within single-payer systems of finance may have more effective policy levers and the countervailing power required to control better the various forms of supply-side moral hazard. ${ }^{32} 34$

Patient-provider informational asymmetry also suggests that patient cost-sharing will be inefficient by leading to non-optimal health care consumption. The fact that patients often cannot distinguish between necessary and unnecessary care, that costsharing discriminates on the basis of ability to pay, and that those with low income, on average, have greater needs for care, means that cost-sharing leads to a reduction in both necessary and unnecessary care, with potentially important adverse health effects. ${ }^{35}$

\section{Key messages}

The key messages of such efficiency analyses are that: (1) it will likely be more costly to produce insurance through private markets than through a public, single-payer system; (2) a system of private insurance markets will be incomplete, leaving members of society with either no insurance or less-than-complete insurance (for reasons other than ability to pay) while public insurance can provide universal coverage; (3) the usual prescription of cost-sharing within insurance systems is not supported in the health care sector. Taken together, they imply that a system of publicly financed insurance is more likely to provide the broad access to and utilisation of health financing demanded by the utilitarian, extra-welfarist and Rawlsian frameworks than is a system of private insurance markets. Indeed, these efficiency arguments, when combined with equity considerations provide a strong rationale for universal, mandatory, first-dollar public insurance for health care. A few qualifications to this general conclusion are required.

Within the utilitarian calculus, the benefits of such a programme of public financing, which provides the same amount of insurance to all members 
of society, would have to be weighed against a welfare cost that arises in a world of heterogeneous risk attitudes and preferences for insurance. A system of public financing that provides everyone with the same level of insurance forces some to consume more insurance than they desire and others less insurance than they desire. The size of this welfare loss depends on the extent of heterogeneity relative to the welfare cost of imperfect market arrangements. The universal programme may still be justified, but technically it becomes an empirical matter.

Secondly, given the correlation between health and other markers of socioeconomic status (for example, income, education, control, etc), the "least advantaged" member of society is likely to be one of those most disadvantaged under private insurance markets and most helped by a system of public financing. Hence, the rationale for public financing is likely to be quite strong within a Rawlsian framework. Similarly, given that within the extra-welfarist framework health can only be equalised by improving the health of those with low health status (recall the side constraint on not lowering the health of anyone), the rationale for public financing is again likely to be quite strong within health-oriented extra-welfarism.

Thirdly, although significant public financing may be a necessary condition for achieving the access and utilisation sought by the different frameworks, the funding, organisation and delivery of services will have an important impact on realising the full vision.

Lastly, the patterns of income redistribution associated with public finance through progressive systems of taxation advance broader social objectives, an aspect not considered above. ${ }^{32}{ }^{34}$ Private insurance with risk-rated premiums does not embody any ex ante redistribution of income (though of course, ex post, it redistributes from the well to the sick in the insurance pool). In contrast, public financing embodies both ex ante redistribution from the wealthy (and generally healthy) to the poor (who generally have lower health status) as well as ex post redistribution from the healthy to the sick.

PUBLIC FINANCING WITH NO PARALLEL PRIVATE FINANCE

The vast majority of countries with universal publicly financed systems of health care insurance allow a parallel private insurance sector in which individuals can purchase private insurance for publicly insured services. The benefits of such insurance to its beneficiaries may include a wider range of treatment choices, the ability to jump a public queue, and so forth. Advocates also argue that such private insurance helps improve access to the public sector by lessening the demands placed on it. Is there an ethical rationale, however, for going beyond the provision of universal public finance by prohibiting such parallel private insurance, as is done in Canada for medically necessary physician and hospital services?
Restricting private insurance this way might follow directly from certain ethical approaches that demand equal access to health care or equal maximum possible consumption of health care by all members of society (for example, perhaps some solidarity-based approaches). It would not, however, follow directly from any of the three ethical frameworks considered in this paper or many other approaches framed within the four propositions identified above. But within a wide range of consequentialist approaches, such a restriction might derive indirectly from the operation of parallel systems of finance. That is, it is an empirical question whether a system of financing that prohibits private insurance for publicly insured services better advances the access and utilisation patterns ethically demanded. Evidence suggests that this is at least plausible.

Parallel systems of private finance can drain resources from the public system, erode public support for the public system, lead to longer waiting times in the public sector, and make it harder to provide all members with timely access to high quality services. ${ }^{36}$ Parallel private insurance is in general associated with an expansion of resources devoted to health care, though these additional resources are often used for services that generate smaller health gains (otherwise, they would have been given greater priority within the public system).

These dynamics imply that a parallel private insurance sector is not, as is commonly suggested, simply an add-on to a publicly financed system. Rather, complex interaction occurs that affects the viability of the publicly financed system, which leads to cross-subsidies (most often from public to private), and which may draw scarce resources into the health sector that are allocated in ways not consistent with the ethically justified patterns of access and utilisation.

Once again, this potential empirical justification is perhaps most tentative within a utilitarian framework, as the benefits of such a restriction on parallel private insurance must be weighed against its cost in the form of frustrated preferences among those who would prefer to purchase such insurance. The rationale is perhaps strongest within the extrawelfarist approach that calls for an equal distribution of health and which strongly de-emphasises utility effects in the valuation process. Given that on average it is those who are of low income and poor health status who are hurt most by the dynamics of parallel systems of finance, such a restriction may well also be supported within a Rawlsian framework.

\section{Conclusions}

My hope is that this short paper has documented at least two contributions of economic reasoning to the development of ethical arguments regarding public financing of health care. First, that economic methods have helped to clarify concepts such as access and need, which are central to discussions of 
ethically justified allocations of health care resources. And second, that economic analysis, which has demonstrated both analytically and empirically that private insurance markets suffer a number of both equity- and efficiency-relevant deficiencies, has a central role to play within a wide range of ethical approaches in identifying the ethically justified institutional arrangements for financing health care. Both of these points exemplify a broader cross-fertilisation between ethics and economics that has emerged in recent years (see, for example,
Sen, Hausman and McPherson, and Broome among others) which promises to advance both disciplines.

Feremiah Hurley, PhD, is Professor in the Department of Economics and Centre for Health Economics and Policy Analysis, McMaster University, Hamilton, Ontario, Canada

\section{References and notes}

1 Health care financing refers to the raising of revenue from individuals in society to support the provision of health care services. Public financing refers to raising the revenues through the public tax system. Financing should be distinguished from delivery. Delivery refers to the actual provision of health care services. There is no logical relationship between the nature (ie, services. There is no logical relationship between the nature (ie, public or private) of financing and the nature (ie, public or private) of the delivery system: public financing can be (and often is) combined with the delivery of health care services by private
organisations (not-for-profit, not-only-for-profit and for-profit organisations (
organisations).

2 Culyer AJ. The normative economics of health care finance and provision. Oxford Review of Economic Policy 1989;5:34-58.

Culyer AJ. Commodities, characteristics of commodities, characteristics of people, utilities and quality of life. In: Baldwin S, Godfrey C, Propper C, eds. Quality of life: perspectives and policies. London: Routledge, 1990: 9-27.

4 Rawls J. A theory of justice. Oxford: Oxford University Press, 1971

5 Wolff RP. Understanding Rawls. Princeton: Princeton University Press, 1977.

6 Sen A. On ethics and economics. Oxford: Blackwell, 1987.

7 Sen A. The standard of living. Cambridge: Cambridge University Press, 1987.

8 Sen A. Commodities and capabilities. Oxford: Oxford University Press, 1999.

9 See reference 4: 92.

10 Culyer AJ, Wagstaff A. Equity and equality in health and health care. Fournal of Health Economics 1993; 2:431-57.

11 Culyer AJ. Equality of what in health policy? Conflicts between the contenders. York: University of York Centre for Health Economcontenders. York: University of Yor
ics, 1995. Discussion paper 142 .

12 Rawls J. Political liberalism. New York: Columbia University Press, 1993.

13 Williams A, Cookson R. Equity in health. In: Culyer AJ, Newhouse JP, eds. Handbook of health economics. Amsterdam: North-Holland, 2000: 1863-910.
14 Health care is sometimes consumed for reasons other than improving health, such as a diagnostic test that provides information valued by the patient even if it will not alter treatment decisions or health. This definition holds true for a large portion of health care consumption.

15 Evans RG, Barer M, Marmor T. Why are some people healthy and others not? New York: DeGrutyer, 1994.

16 Mooney G. Equity in health care: confronting the confusion. Effective Health Care 1983;1:179-85.

17 Mooney G. Key issues in health economics. New York: Harvester Wheatsheaf, 1994.

18 LeGrand J. Equity and choice. London: HarperCollins Academic, 1991.

19 Pereira J. What does equity in health mean? fournal of Social Policy 1993;21:19-48.

20 Wagstaff A, Van Doorslaer E. Equity in health care finance and delivery. In: Culyer AJ, Newhouse JP, eds. Handbook of health economics. Amsterdam: North-Holland, 2000: 1803-62.

21 Williams A. Need-an economic exegesis. In: Culyer AJ, Wright KG, eds. Economic aspects of health. London: Martin Robertson, 1978: 32-45.

22 Olsen EO, Rogers DL. The welfare economics of equal access. fournal of Public Economics 1991;45:91-105.

23 Culyer AJ. Need - is a consensus possible? Fournal of Medical Ethics 1998;24:77-80.

24 Robertson A. Critical reflections on the politics of need: implications for public health. Social Science and Medicine 1998;47: 1419-30.

25 Braybrooke D. Meeting needs. Princeton: Princeton University Press, 1987.

26 Barry B. Political argument. London: Routledge, 1965.

27 Thomson G. Needs. London: Routledge and Kegan Paul, 1987.

28 Springborg P. The problem of human needs and the critique of civilization. London: George Allen and Unwin, 1991.

29 Culyer AJ, Simpson H. Externality models and health: a Rückblick over the last twenty years. Economic Record 1980;56:22230.

30 Evans RG, Wolfson AD. Faith, hope and charity: health care in the utility function. Vancouver, BC: University of British Columbia, 1980. Discussion paper 20-46.

31 Nicholson W. Efficiency and welfare. Intermediate microeconomics and its application. New York: Dryden Press, 1983: 541-69, at 542 .

32 Evans RG. Strained mercy: the economics of Canadian health care. Toronto: Butterworths, 1984

33 Woolhandler S, Himmelstein D. The deteriorating efficiency of the US health care system. New England fournal of Medicine 1991;324:1253-8.

34 Evans RG. The welfare economics of public health insurance: theory and Canadian practice. In: Soderstrom L, ed. Social insurance. Amsterdam: North Holland, 1983: 71-103.

35 Stoddart GL, Barer M, Evans RG. User charges, snares and delusions: another look at the literature. Toronto: Premier's Council on Health, Well-being and Social Justice, 1994

36 MacDonald P, Shortt S, Sanmartin C, Barer M, Lewis S, Sheps S. Waiting lists and waiting times for heatlh care in Canada: more management!! More money?? Ottawa: Health Canada, 1998.

37 Hausman D, McPherson MS. Economic analysis and moral philosophy. New York: Cambridge University Press, 1996.

38 Broome J. Weighing goods. Oxford: Basil Blackwell, 1991.

39 Broome J. Ethics out of economics. Cambridge: Cambridge University Press, 1999. 